ARTICLE

https://doi.org/10.1038/s41467-020-15883-9

\title{
Mapping global carbon footprint in China
}

\author{
Yuantao Yang ${ }^{1,2,3,4}$, Shen Qu (i] ${ }^{4 凶}{ }^{\star}$, Bofeng Cai ${ }^{5}$, Sai Liang ${ }^{6}{ }^{6}$, Zhaohua Wang ${ }^{1,2,3}$, Jinnan Wang ${ }^{5} \&$ \\ Ming $X u(1){ }^{4,7}$
}

Developing localized climate mitigation strategies needs an understanding of how global consumption drives local carbon dioxide $\left(\mathrm{CO}_{2}\right)$ emissions with a fine spatial resolution. There is no study that provides a spatially explicit mapping of global carbon footprint in China_- the world's largest $\mathrm{CO}_{2}$ emitter_— simultaneously considering both international and interprovincial trade. Here we map $\mathrm{CO}_{2}$ emissions in China driven by global consumption in 2012 at a high spatial resolution $(10 \mathrm{~km} \times 10 \mathrm{~km})$ using a detailed, firm-level emission inventory. Our results show that the carbon footprints of foreign regions in China are concentrated in key manufacturing hubs, including the Yangtze River Delta, Pearl River Delta, and North China Plain. Approximately $1 \%$ of the land area holds $75 \%$ of the global carbon footprint in China. The carbon footprint hotspots in China identified are the key places in which collaborative mitigation efforts between China and downstream parties that drive those emissions.

\footnotetext{
${ }^{1}$ School of Management and Economics, Beijing Institute of Technology, 100081 Beijing, People's Republic of China. ${ }^{2}$ Center for Sustainable Development and Intelligent Management Research, Beijing Institute of Technology, 100081 Beijing, People's Republic of China. ${ }^{3}$ Center for Energy and Environmental Policy Research, Beijing Institute of Technology, 100081 Beijing, People's Republic of China. ${ }^{4}$ School for Environment and Sustainability, University of Michigan, Ann Arbor, MI 48109-1041, USA. ${ }^{5}$ Center for Climate Change and Environmental Policy, Chinese Academy for Environmental Planning, 100012 Beijing, People's Republic of China. ${ }^{6}$ State Key Joint Laboratory of Environment Simulation and Pollution Control, School of Environment, Beijing Normal University, 100875 Beijing, People's Republic of China. ${ }^{7}$ Department of Civil and Environmental Engineering, University of Michigan, Ann Arbor, MI 481092125, USA. ${ }^{凶}$ email: shenquin@umich.edu
} 
nternational trade separates greenhouse gas (GHG) emissions from consumption drivers ${ }^{1-4}$. Globally, large shares of products and services are not consumed locally, which leads to considerable embodied emissions driven by global supply chains. This separation between GHG emissions and final consumption, in turn, undermines local mitigation efforts ${ }^{5}$.

Carbon footprint (CF) accounting (i.e., consumption-based accounting) tracks the GHG emissions driven by supply chains and allocates the mitigation responsibilities to final consumers ${ }^{6-10}$. Previous work has linked GHG emissions to final consumption, but primarily at the national ${ }^{11-15}$ or regional ${ }^{1,16-19}$ levels. Given the increasing importance of non-state actors_- provinces/ states, cities, and companies__ in climate mitigation, it becomes increasingly important to spatially explicitly link final consumers to subnational actors that have direct control over GHG emissions.

China, the world's largest GHG-emitting nation ${ }^{20}$, has long been the primary producer of various industrial and consumer products. A significant share of China's GHG emissions can be attributed to the final consumption of other nations and regions, given that approximately one-quarter of China's gross domestic product (GDP) is from exports. Existing studies have investigated global CFs in China at the national level ${ }^{14}$ or at the provincial level considering the interregional trade within China ${ }^{1}$, but without spatially explicit emission profiles. Although global CFs hotspots have been spatially explicitly mapped for nations worldwide including China ${ }^{21}$, interregional trade within China was not considered. Given the heterogeneities of regional economies within China, the CFs of producing the same product can be significantly different across regions ${ }^{22}$. To the best of our knowledge, there is no assessment of spatially explicit CF in China that considers both international and interprovincial trade. The lack of such information can lead to misinterpretation of the linkage between emissions and final consumers. The failure to trace emission drivers along both international and interprovincial supply chains could further obstruct climate mitigation efforts for non-state actors in China.

Here, we spatially explicitly link carbon dioxide $\left(\mathrm{CO}_{2}\right)$ emissions within mainland China to final consumers worldwide through both international and interprovincial trade in 2012. Specifically, we first nest an interprovincial multi-regional inputoutput (MRIO) model for China ${ }^{23}$ into a global MRIO model ${ }^{24}$. We then link the most recent and detailed spatially explicit $\mathrm{CO}_{2}$ emission inventories of $\mathrm{China}^{25}$ to the nested MRIO model. These high-quality and fine-scale inventories are derived from large-scale, bottom-up surveys of individual firms in all industries that generate $\mathrm{CO}_{2}$ emissions. The resulting $\mathrm{CF}$ maps show the locations and magnitudes of a region's CF in China at a spatial resolution of $10 \times 10 \mathrm{~km}$. These detailed CF maps offer insights to guide consumption-based policymaking to avoid carbon leakage and identify emission hotspots for targeted mitigation opportunities for non-state actors in China.

\section{Results}

Carbon footprint hotspots in China in 2012. The CF hotspot map in Fig. 1a identifies the location of $\mathrm{CO}_{2}$ emissions in China driven by foreign final consumption in 2012. The total CF driven by foreign final consumption is 1466 million tonnes (Mt), which accounts for $14.6 \%$ of the total industrial-related $\mathrm{CO}_{2}$ emissions in China in 2012. This emission volume (1466 Mt) ranks the 5 th

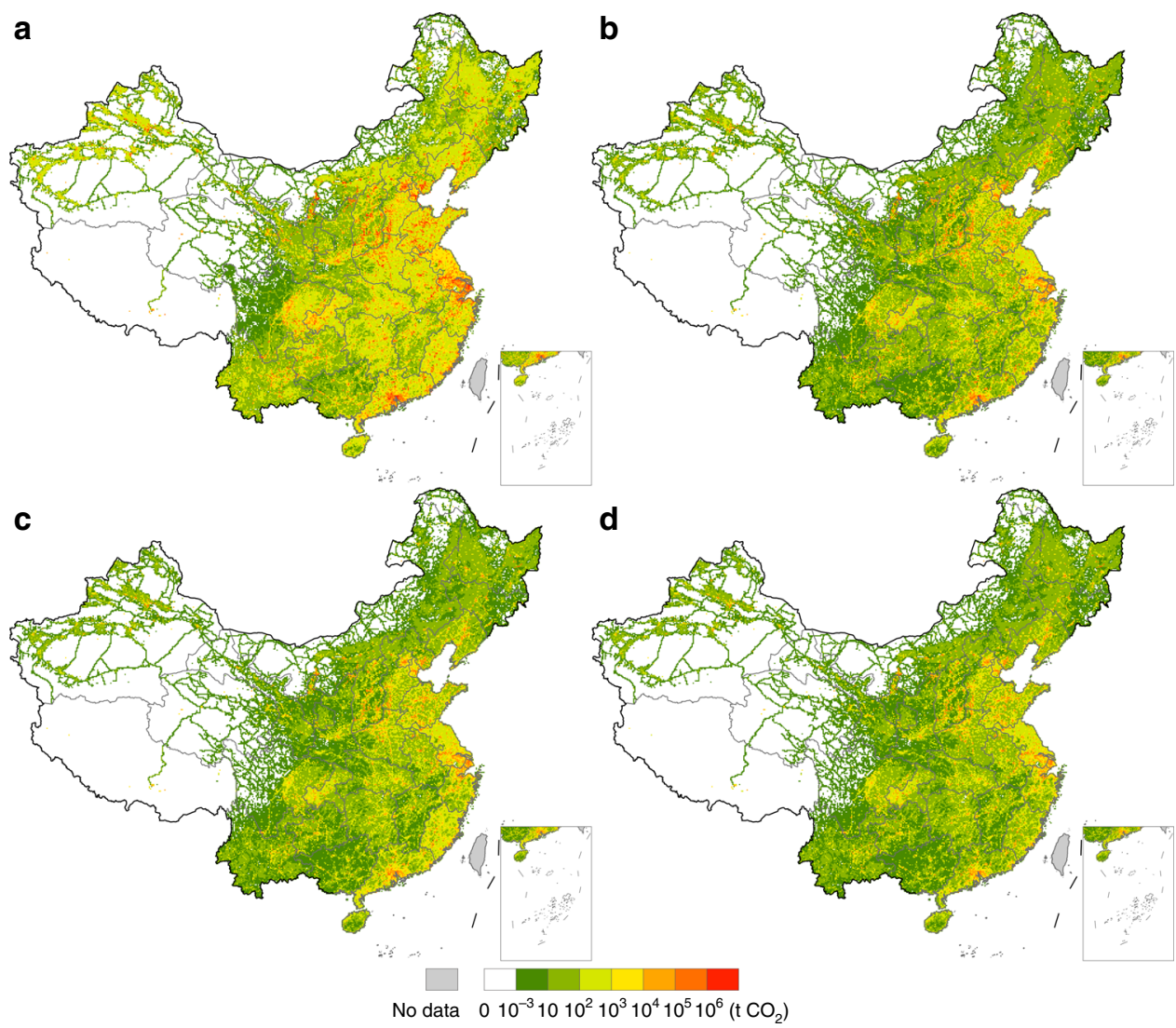

Fig. 1 Carbon footprint hotspots of global and regional consumptions in mainland China in 2012. a shows carbon footprint (CF) hotspots of foreign final consumption. b-d show carbon footprint hotspots of the consumption of the United States, Hong Kong, and Japan, respectively. Among all foreign regions, the United States, Hong Kong, and Japan have the largest CFs in China, contributing $23.0 \%, 10.8 \%$, and $9.0 \%$, respectively, to the total foreign CF in China in 2012. 
in the world only after the mainland China, the United States (US), India, and Russia ${ }^{26}$.

The CF hotspots in China driven by global consumption mainly emerge in cities in the Yangtze River Delta (e.g., Shanghai, Ningbo, Suzhou (Jiangsu), Xuzhou, Nanjing), North China Plain (e.g., Tianjin, Tangshan, Beijing, Handan), and Pearl River Delta (e.g., Dongguan, Guangzhou, Foshan). All cities are listed in descending order in terms of their CFs (hereafter). These areas are global hubs of manufacturing and exports for many industrial and consumer products. The emissions from these regions are closely linked with global consumption through downstream supply chains. Additional CF hotspots are scattered across northern, central, and southern China, where key manufacturing industries are located, such as in Ordos, Panzhihua, Linfen, and Pingdingshan.

As China's largest export destination, the US is also responsible for the largest share of the global CF in China. Hotspots for the US CF in China are located in the Yangtze River Delta notably in the cities of Shanghai, Suzhou, Ningbo, Xuzhou, Pearl River Delta concentrated in the cities of Dongguan, Guangzhou, Foshan, Huizhou, and Jing-Jin-Ji region particularly in the cities of Tianjin and Tangshan (Fig. 1b). All these cities are key manufacturing bases in China, and most of them have or are close to ports for maritime shipping. Exports from these ports drive large amounts of $\mathrm{CO}_{2}$ emissions in these cities. Given the pivotal role in trading with China, disaggregated analysis of $\mathrm{CF}$ hotspots for the US is presented in a later subsection.

Hong Kong, a special administrative region of China, relies heavily on mainland China for its consumption. Moreover, a large share of China's exports is re-exported through Hong Kong. As a result, Hong Kong has a large CF in mainland China. Approximately $70 \%$ of Hong Kong's CF in China is driven by household final consumption (44.9\%) and gross fixed capital formation (25.7\%). The CF hotspots of Hong Kong in mainland China are mainly located in the Yangtze River Delta, particularly in the cities of Shanghai, Ningbo, and Suzhou, and Pearl River Delta, concentrated in the cities of Dongguan, Guangzhou, and Foshan. Additional hotspots can be found in the cities of Tianjin, Tangshan, Beijing, and Ordos (Fig. 1c).

Japan is the world's third largest economy and China's second largest export destination just after the US (excluding Hong Kong). Notable CF hotspots of Japan in China are in the cities of Shanghai, Ningbo, and Suzhou in the Yangtze River Delta and are also scattered across the coastal region in the North China Plain (Fig. 1d). Nearly 90\% of Japan's CF in China is driven by household final consumption (63.1\%) and gross fixed capital formation (26.2\%).

The rest of the ten regions with the largest CFs in China are Germany, Great Britain, South Korea, India, Canada, France, and Italy. The Supplementary Figs. 1-7 provide each region's CF hotspot map in mainland China.

Global CF hotspots in China are spatially concentrated in a small area of land. As shown in Fig. 2, only 1\% of China's land area encompasses $\sim 75 \%$ of the CF of global consumption. Only slightly $>2.2 \%$ of the land area in China is needed for $90 \%$ of the CF. This relatively small area of land corresponds to the manufacturing hubs in China__-Yangtze River Delta, Pearl River Delta, and North China Plain- where $\mathrm{CO}_{2}$ emissions occur as a result of producing goods for export.

The spatial distribution of these export-driven $\mathrm{CO}_{2}$ emissions is quite different from that of the simple proportional (i.e., 14.6\%) emissions directly obtained from the China High Resolution Emission Database (CHRED). To see this, we map the difference between these two results (the $14.6 \%$ of CHRED emission map minus the export-driven CF hotspot result) in Fig. 3. Great differences can be seen in these $10 \times 10 \mathrm{~km}$ grids ranging from

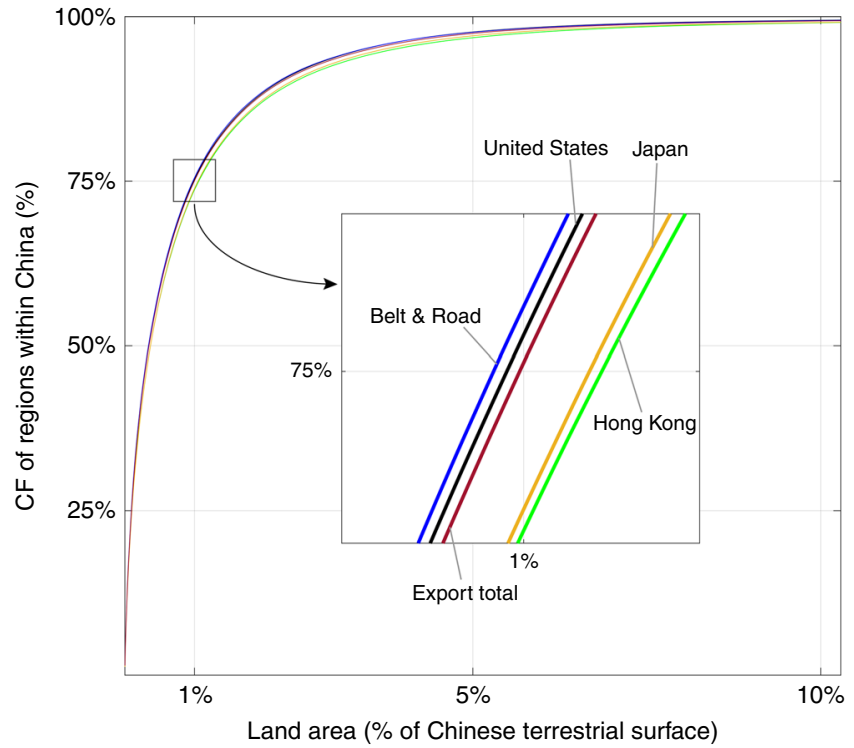

Fig. 2 Spatial spread of CF of selected regions in China in 2012. It shows the minimum fraction of the Chinese land area required to hold the CFs of regions. The horizontal axis represents the shares of the land area of the Chinese terrestrial surface, and the vertical axis represents the proportions of CF within China.

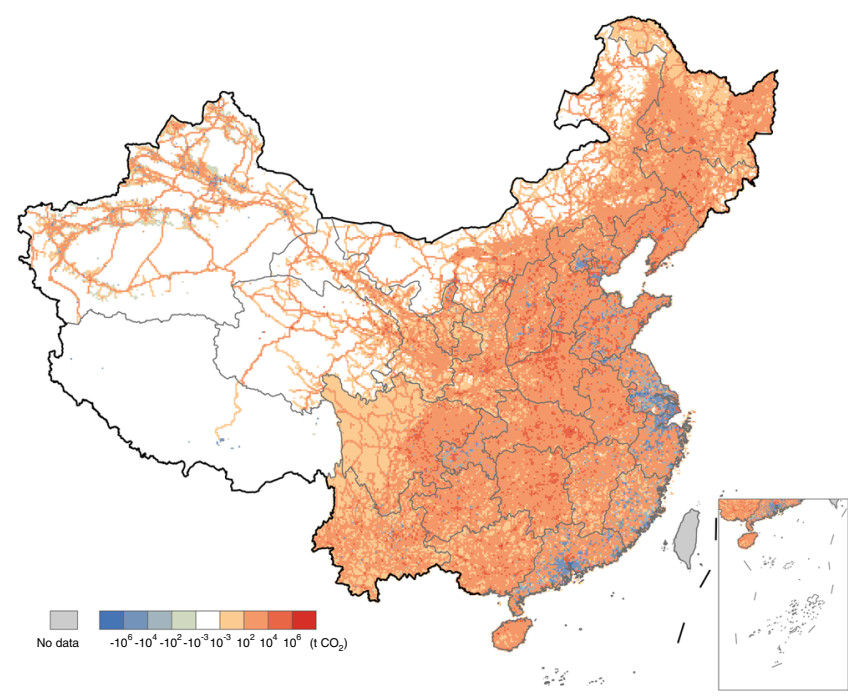

Fig. 3 Emission differences between $14.6 \%$ of the original CHRED emission map and the export-driven carbon footprint map. Blue grids mean that $14.6 \%$ of the original CHRED emissions in these grids are less than the export-driven carbon footprint, while red grids imply the opposite.

approximately $-13.7 \mathrm{Mt}$ in northern Shanghai to $\sim 2.2 \mathrm{Mt}$ in eastern Pingdingshan. The differences mainly locate in cities in the Yangtze River Delta particularly in the cities of Shanghai (37.9 Mt in total absolute difference (the sum of the absolute values of the difference of all the emission grids within a specific city's boundary) and $-33.7 \mathrm{Mt}$ in total actual difference (the sum of the actual values of the difference of those grids)), Ningbo (16.0 and -15.5 Mt), Suzhou (12.6 and $-12.4 \mathrm{Mt})$, and Pearl River Delta notably in the cities of Guangzhou (10.1 and -8.6 Mt), Foshan (8.1 and -8.0 Mt), Huizhou (6.8 and $-6.3 \mathrm{Mt})$. Other notable differential emissions can be seen in the cities of Beijing (7.2 and $-3.4 \mathrm{Mt})$, Pingdingshan (6.0 and 6.0 Mt), Wuhan (4.8 and $4.8 \mathrm{Mt}$ ), and so on. These differential hotspots indicate the importance of improving the accuracy of $\mathrm{CF}$ analysis within China. 
a

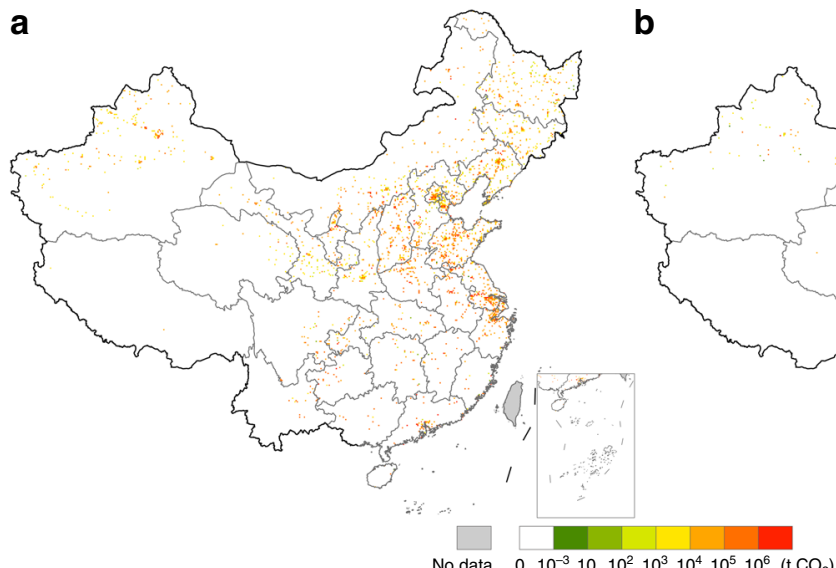

b

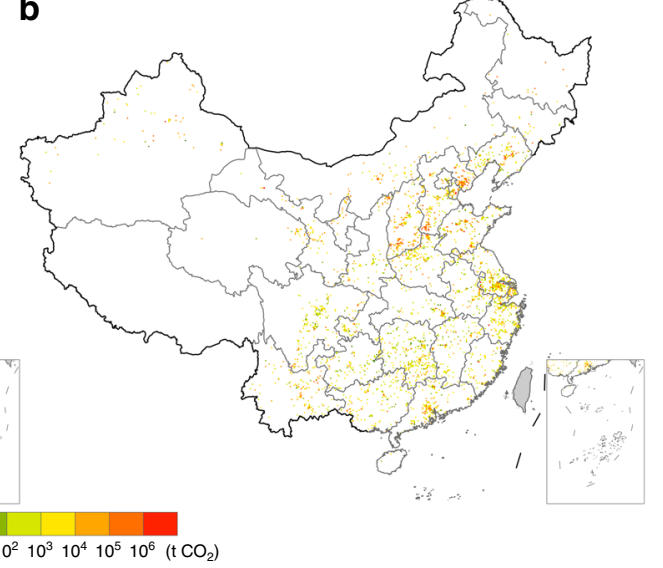

Fig. 4 Export-driven carbon footprint hotspots in two different sectors in China. a shows the carbon footprint hotspots driven by export in production and supply of electricity, steam, gas, and water sector, and $\mathbf{b}$ shows the carbon footprint hotspots driven by export in smelting and processing of metals sector.

Carbon footprint hotspots in China by sectors. Among all the exporting sectors, energy-intensive industries are the main contributors. They are production and supply of electricity, steam, gas, and water sector (S22, 42.3\%), smelting and processing of metals sector (S14, 13.6\%), nonmetallic mineral products sector (S13, 11.5\%), petroleum refining, coking, and processing of nuclear fuel sector (S11, 8.7\%), and chemical products sector (S12, 7.9\%). The contributions of other industries are relatively small, ranging from $0.03 \%$ for other manufacture sector (S20) to $3.9 \%$ for mining and washing of coal sector (S2).

$\mathrm{S} 22$ is the largest $\mathrm{CO}_{2}$-emitting sector in China, accounting for $40.2 \%$ of the industrial-related $\mathrm{CO}_{2}$ emissions in China in 2012. Owing to the resource endowment in China, coal takes the major proportion in the energy mix of power generation, resulting in significant amounts of emissions from it. Also, its emission intensity $\left(\mathrm{CO}_{2}\right.$ emissions per unit output) is the largest among all 25 sectors in 23 out of the 31 provinces, ranging from $0.73 \mathrm{tCO}_{2} /$ $\mathrm{kUSD}$ in Beijing to $11.76 \mathrm{tCO}_{2} / \mathrm{kUSD}$ in Inner Mongolia. From the data in China's MRIO table, we can see that only eight provinces, including Guangdong, Yunnan, Guangxi, Inner Mongolia, Beijing, Jilin, Xinjiang, and Heilongjiang (in descending order of exporting value) exported electricity in 2012 and the exporting value accounts for only $0.06 \%$ of the total export ${ }^{23}$. Exports of electricity to countries that are not adjacent to China such as the US and Japan are due to the use of electricity in China by foreign airplanes or vessels. Export-driven CF in S22 in one province of China can be driven directly by the export of S22 product (electricity) and indirectly by the export of other products, causing a significant amount of CF across mainland China (Fig. 4a). The CF hotspots in S22 can be found mainly in the Bohai Rim and Yangtze River Delta concentrated in the cities of Shanghai, Ningbo, and Zhenjiang. Additional hotspots can be found across northern China, especially in the northwestern and northeastern regions where many power plants are located.

China is the largest steel producer in the world as well as the largest exporter ${ }^{27}$. Exports lead to notable CF hotspots in S14 in northern Shanghai, and the cities of Tangshan and Handan in Hebei Province, Linfen and Yuncheng in Shanxi Province, and Anshan and Benxi in Liaoning Province (Fig. 4b). These cities are the main manufacturing bases of iron and steel that use a large amount of coal. Unlike the CF hotspots in S22 that driven by exports, many CF hotspots in S14 caused by exports are also scattered across southern China.

CF hotspots in S13, S11, and S12 in China that driven by exporting products show different spatial distribution patterns (see Supplementary Fig. 8a-c). The CF hotspots in S13 in China caused by exports are mainly distributed below the HeiheTengchong Line, notably in Qingyuan, Foshan, Zhaoqing, and Huizhou in Guangdong Province and Longyan in Fujian Province (Supplementary Fig. 8a). Among them, Qingyuan, Huizhou, and Longyan are three of the top ten origins for cement production. The CF hotspots in S11 driven by exports are concentrated in Shanghai, Tangshan, Tianjin, and the central region of the North China Plain (Supplementary Fig. 8b), where some large refineries are located. Additional hotspots can be found in Dalian, Guangzhou, and Ningbo. For S12, the export-driven CF hotspots are located in the Yangtze River Delta and Pearl River Delta in the cities of Shanghai, Huizhou, Yangzhou, and Zhenjiang (Supplementary Fig. 8c).

Carbon footprint hotspots in China by final demand categories. Among the six categories of final demand (see Methods), household final consumption drives approximately half of the total CF of Chinese exports (48.4\%), followed by gross fixed capital formation $(28.5 \%)$. The majority of Chinese exports are consumer products and intermediate products used to produce consumer products in other regions. Therefore, household final consumption is the largest driver of the global CF in China. In contrast, China's domestic final demand is dominated by gross fixed capital formation due to rapid infrastructure development and urbanization. As a result, the CF of Chinese domestic consumption is largely affected by gross fixed capital formation $(65.1 \%)$, followed by urban household consumption (19.5\%) and rural household consumption (6.2\%).

The CF hotspots of global household final consumption are mostly located in cities of the Yangtze River Delta and Pearl River Delta, such as Shanghai, Ningbo, Suzhou, Dongguan, and Guangzhou (Fig. 5a). The CF hotspots of global gross fixed capital formation are primarily in the Yangtze River Delta, including the cities of Shanghai, Suzhou, Ningbo, and Nanjing. Additional hotspots can be observed in the cities of Anshan, Pingdingshan, Shaoguan, Panzhihua, and Benxi, which are key hubs of steel production in China (Fig. 5b).

Carbon footprint hotspots of the United States. In 2012, the US was the largest driver of $\mathrm{CO}_{2}$ emissions in China (337 Mt), nearly half of which were driven by its household final consumption (49.2\%), followed by gross fixed capital formation (17.1\%), non-profit institutions serving households (11.9\%), government 
a

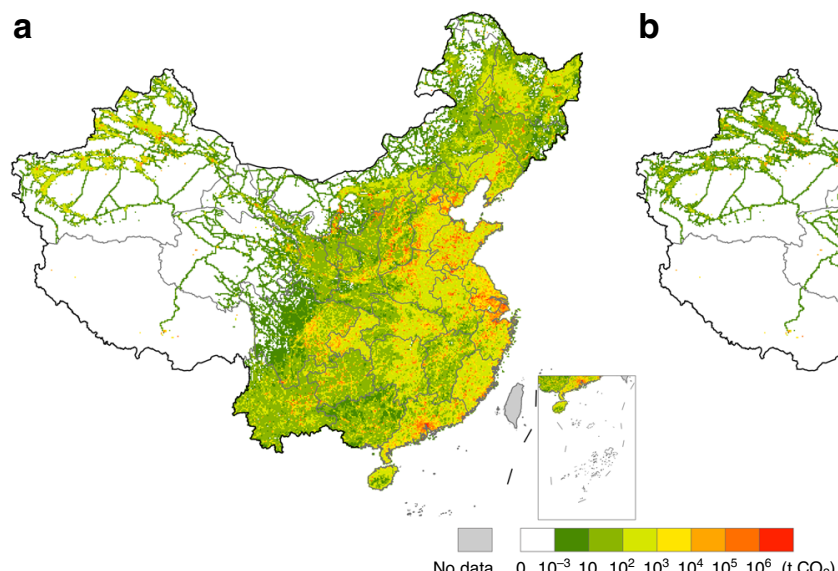

b

Fig. 5 Carbon footprint hotspot maps driven by exports for two different categories of final demand. a shows the carbon footprint hotspots driven by exports for household consumption, and $\mathbf{b}$ shows the carbon footprint hotspots driven by exports for gross fixed capital formation.

a

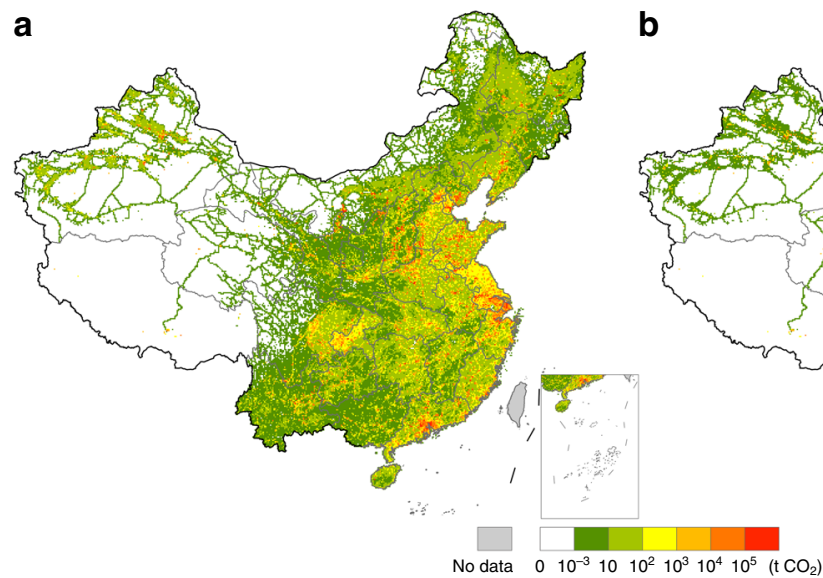

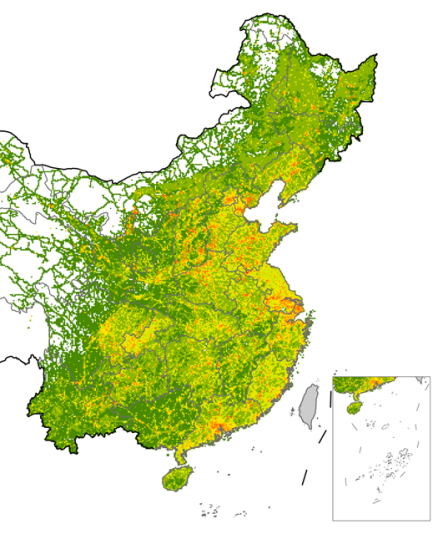

E


hotspots that have frequently been identified above, including the cities of Qingyuan, Chongqing, Longyan, Foshan, and Zhaoqing (Supplementary Fig. 9c).

The spatial distribution of CF hotspots driven by the US gross fixed capital formation shows differences: these hotspots are mainly located in Shanghai, Suzhou, Tangshan, and Tianjin (Fig. 6b). Shanghai is one of the top-emitting cities in China (2.09\% of national total) and has already been identified in CF hotspots analysis for household final consumption. Suzhou and Tianjin are leading high-tech industrial cities in China and produce significant amounts of emissions $(1.13 \%$ and $1.56 \%$ of national total, respectively). Tangshan is a world-famous heavy industry city for its commanding lead in iron and steel production, making it another top $\mathrm{CO}_{2}$-emitting city in China ( $1.81 \%$ of national total). These cities together provide materials and products for electronic equipment and machinery production in coastal China which are in turn exported for global capital formation. Apart from those hotspot cities also identified for the household final consumption CF, hubs of iron and steel manufacturing, such as Anshan, Pingdingshan, and Panzhihua, are also hotspot cities for the gross fixed capital formation CF.

From the sectoral perspective, the CF from S22 accounts for $41.3 \%$ of the total CF driven by the US gross fixed capital formation. The exports for the US gross fixed capital formation are mainly products from S19 and S16 and the production of these high-tech and heavy equipment and machinery requires great amounts of electricity. The hotspots mainly emerge in the North China Plain and the Yangtze River Delta, including the cities of Shanghai, Suzhou, Xuzhou, and Ningbo (Supplementary Fig. 9d). The sectors S14 and S13 contribute $17.0 \%$ and $16.4 \%$, respectively. The CF hotspot distributions for these two sectors are quite similar to the aforementioned distribution of household final consumption CF (Supplementary Fig. 9e, f).

\section{Discussion}

Through this study, we show that most of the CF of China's export occurs in a small number of hubs occupying a small portion of land area in China. Our results for 2012 show that $14.6 \%$ of China's industrial-related $\mathrm{CO}_{2}$ emissions were driven by foreign final consumption. The CF hotspots are mainly located in the Yangtze River Delta, Pearl River Delta, and North China Plain, notably in the cities of Shanghai, Ningbo, Suzhou (Jiangsu), Tianjin, Tangshan, Xuzhou, Nanjing, and Dongguan. The US, Hong Kong, and Japan are the top three regions with the largest CFs in China. Overall, $1 \%$ of land area in China can serve $\sim 75 \%$ of global CFs, while $90 \%$ of global CFs need only slightly $>2.2 \%$ of the land area. Approximately $42 \%$ of the export-driven $\mathrm{CO}_{2}$ emissions in China are emitted by the electricity industry with notable CF hotspots in the cities of Shanghai, Ningbo, Suzhou, and Xuzhou. Meanwhile, over $10 \%$ of the total global CF in China has arisen from both steel and cement industries. The exportdriven CF hotspots in the steel industry mainly emerge in the cities of Shanghai, Tangshan, Handan, Nanjing, and Anshan, while exports generate CF hotspots in the cement industry mainly in the Pearl River Delta.

From the perspective of economic theory, the optimal abatement strategy for $\mathrm{CO}_{2}$ emissions would simply equalize the marginal abatement costs. In the real world, transaction costs, including acquiring reliable information and drafting detailed contracts, prevent this ideal situation ${ }^{10}$. Emission mitigation actions could exert adverse social impacts, such as habitability changes and poverty. In some areas, these actions could decrease employment due to the shutdown of manufacturing enterprises. On the other hand, the internationally transferred mitigation outcomes, as specified in Article 6(2) of the Paris Agreement, recognize nations' contributions to reduce carbon emissions outside their borders ${ }^{32}$. Consumers and intermediate producers may be willing to clean up the carbon emissions along their supply chains for their consumption, which could even add to nationally determined contributions, but lack the relevant information. The spatially explicit CF maps provide more accurate and detailed local assessments with sector- and category-wise results, which can benefit the collaborative policymaking for localized mitigation strategies.

The spatially explicit CF analysis contributes to sustainable production, interregional and international trade, and consumption ${ }^{33}$. Responsibility for the great amount of $\mathrm{CO}_{2}$ emissions $(1466 \mathrm{Mt})$ driven by China's export should be shared along the international supply chains but not exclusively on emitting industries in China or on global final consumers. The CF maps are more actionable than a proportional emission map of the total emissions, for both producers in China and consumers abroad, to initiate collaborative mitigation efforts on targeted CF hotspots.

Given the current US-China trade dispute, reduced exports from China to the US are expected for goods that are affected by US tariffs. As a result, the CF hotspot map for China's export to the US will change accordingly. Approximately half (50.2\%) of tariffs that are currently imposed on imports from China are related to electromechanical equipment; and the levy on furniture and lighting, base metal, and transportation equipment account for $12.0 \%, 6.9 \%$, and $6.2 \%$, respectively ${ }^{34}$. As a result, the CF of the US in China will likely decline accordingly in the cities of Chongqing, Ningbo, Shanghai, Langfang, etc.

China's Belt and Road Initiative is expected to strengthen the trade relationship between China and the Belt and Road nations $\left(\sim 140\right.$ nations until Jan $\left.2020^{35}\right)$, which are mostly located in the Eurasia continent, especially for the ASEAN (Association of Southeast Asia Nations). Our results for 2012 show that the CF hotspots of the Belt and Road nations are widely spread in eastern, central, and northern China (Supplementary Fig. 10). In recent years, the export from China to Belt and Road partner nations mainly focuses on mechanical and electrical equipment and material for transportation infrastructure (i.e., highway, railway, ports, etc.) and energy infrastructure. In the future, it may shift to the export of high-quality production capacity such as high-ending manufacturing, information technology, internet applications, etc. Therefore, these expected increases in exports from China will create more demands for electrical machinery, electronic equipment, etc., and the CF will possibly increase accordingly in the cities of Kunming, Nanjing, Ningbo, etc. Mitigation strategies need to be in place to face the anticipated emission increase in these places.

Uncertainties exist due to inherent assumptions of the MRIO model $^{36-38}$. China is a vast country with multiple industrial clusters and economic zones, some of which are supported by foreign direct investments (FDI) to produce exported commodities. Therefore, nations may have different interregional supply chains within China, leading to different spatial distributions of emission hotspots induced by the same category of exported commodities. In this study, we disaggregate and allocate the export of each product category in each province to the exporting regions assuming that the distribution shares are the same as the corresponding ones at the national level. This assumption may not be consistent with reality and is a limitation of the approach applied here, which results from data unavailability. On the other hand, China's exports are mainly through the developed eastern coast regions that are equipped with many world-class ports ${ }^{39}$. The primary driving force of international trade is low transportation costs of ocean shipping ${ }^{40}$, and the transportation costs for imports from China's coastal regions should have little difference. Under this perspective, our assumption on provincial 
distribution shares of exports seems reasonable. In the future, international trade data on provincial exports by destination and imports by origin can greatly improve the results. Even the integration of China's interprovincial MRIO model with a global MRIO model represents a significant improvement over the previous investigation on spatially explicit CFs in China, more accurate estimations based on an inter-city input-output model may still be desirable. Currently, such a model does not exist, and its development can provide a critical contribution to the measurement of global CFs in China.

With the same approach, spatially explicit hotspots of other air pollutants and broadly other environmental impacts can also be identified. Future work may also examine the temporal and spatial dynamics of global environmental footprint hotspots in China. Such information has become increasingly needed for non-state actors to participate in global mitigation of various environmental impacts.

\section{Methods}

Linking the China MRIO model to the Eora MRIO model. The 2012 MRIO model for China is in a 31-province and 42-sector format ${ }^{23}$. The global MRIO model for 2012 is from Eora ${ }^{24,37}$ with 190 nations/regions and 14,839 sectors. The spatially explicit gridded $\mathrm{CO}_{2}$ emissions maps for all two-digit International Standard Industrial Classification sectors in 2012, with a resolution of $10 \times 10 \mathrm{~km}$, are from the China High Resolution Emission Database (CHRED) ${ }^{25,41}$.

We disaggregate the Chinese portion in Eora into a 31-province table according to the China MRIO model. To keep the spatial emission data of each sector consistent with the economic sectors in the China MRIO model, we first aggregate the China MRIO model and emissions data into a 31-province and 25-sector format (Supplementary Table 1). Based on the original Eora's export and import proportions for China, the export and import for each sector in each province in the China MRIO model are disaggregated by the remaining 189 nations/regions. We assume that the international exports (or imports) of each sector in a province are distributed among all global regions in the same proportions as those of China's total exports (or imports). Altogether, the updated global MRIO model contains 189 regions with the same sectors as those in the original Eora model and 31 Chinese provinces with 25 sectors in each province. Previous research on the impacts of trade on China's carbon emissions has embedded the China MRIO model into the global MRIO model using the same approach ${ }^{1,17,18}$. Theoretically, this method of combining different MRIO models is equivalent to assembling a network and has the properties of transparency, modularity, and efficiency ${ }^{42}$. However, the quantification of global carbon footprint can be further improved once data on country-specific regional heterogeneity of supply chains become available.

The final demand categories of global regions include household final consumption, non-profit institutions serving household, government final consumption, gross fixed capital formation, changes in inventories, and acquisition less disposals of valuables ${ }^{24}$. For Chinese provinces, final demand is categorized into rural household consumption, urban household consumption, government consumption, gross fixed capital formation, and stock change ${ }^{23}$.

Mapping global carbon footprint in China. We first conduct an environmentally extended MRIO analysis to trace embodied $\mathrm{CO}_{2}$ emissions to final consumption along the global supply chains. The basic linear equations of the MRIO model are

$$
\mathbf{x}=(\mathbf{I}-\mathbf{A})^{-1} \mathbf{Y}=\mathbf{L Y}
$$

$$
\begin{aligned}
\mathbf{x} & =\left[\begin{array}{c}
\mathbf{x}^{1} \\
\mathbf{x}^{2} \\
\vdots \\
\mathbf{x}^{n}
\end{array}\right], \mathbf{L}=\left(\mathbf{I}-\left[\begin{array}{cccc}
\mathbf{A}^{11} & \mathbf{A}^{12} & \ldots & \mathbf{A}^{1 n} \\
\mathbf{A}^{21} & \mathbf{A}^{22} & \ldots & \mathbf{A}^{2 n} \\
\vdots & \vdots & \ddots & \vdots \\
\mathbf{A}^{n 1} & \mathbf{A}^{n 2} & \ldots & \mathbf{A}^{n n}
\end{array}\right]\right)^{-1} \\
& =\left[\begin{array}{cccc}
\mathbf{L}^{11} & \mathbf{L}^{12} & \ldots & \mathbf{L}^{1 n} \\
\mathbf{L}^{21} & \mathbf{L}^{22} & \ldots & \mathbf{L}^{2 n} \\
\vdots & \vdots & \ddots & \vdots \\
\mathbf{L}^{n 1} & \mathbf{L}^{n 2} & \ldots & \mathbf{L}^{n n}
\end{array}\right], Y=\left[\begin{array}{c}
\sum_{t} \mathbf{y}^{1 t} \\
\sum_{t} \mathbf{y}^{2 t} \\
\vdots \\
\sum_{t} \mathbf{y}^{n t}
\end{array}\right]
\end{aligned}
$$

where $\mathbf{x}=\left(x_{j}^{s}\right)$ is the total output vector in which $x_{j}^{s}$ is the total output of sector $j$ in region $s ; \mathbf{A}^{r s}=\left(a_{i j}^{r s}\right)$ is the technical coefficient submatrix given by $a_{i j}^{r s}=z_{i j}^{r s} / x_{j}^{s}$, in which $z_{i j}^{r s}$ is the intersectoral monetary flow from sector $i$ in region $r$ to sector $j$ in region $s ; \mathbf{L}=(\mathbf{I}-\mathbf{A})^{-1}=\left(l_{i j}^{r s}\right)$ is the Leontief inverse matrix in which $l_{i j}^{r s}$ capture both direct and indirect inputs from sector $i$ of region $r$ to satisfy one unit of final demand in monetary value in sector $j$ in region $s$, and $\mathbf{I}$ is the identity matrix ${ }^{43}$; $\mathbf{Y}=\left(y_{j}^{s t}\right)$ is the final demand matrix in which $y_{j}^{s t}$ is the final demand of region $t$ for products of sector $j$ from region $s$.

The $\mathrm{CO}_{2}$ emissions embodied in the products of a sector in a specific region can be calculated by extending the MRIO model with an emission intensity vector $\mathbf{f}$, entries in which, $f_{i}^{r}$, show the $\mathrm{CO}_{2}$ emissions per unit of economic output for sector $i$ in region $r$ :

$$
\mathbf{C}=\hat{\mathbf{f} L Y}
$$

The figures presented in this paper are the CF hotspots in China driven by the final demand of region $t$ :

$$
H^{t}=\sum_{i} M_{i}^{r} \frac{f_{i}^{r} \sum_{j s} l_{i j}^{r s} y_{j}^{s t}}{d_{i}^{r}}
$$

where $M_{i}^{r}$ is the gridded emission map term showing the $\mathrm{CO}_{2}$ emissions of sector $i$ in each grid in region $r$, and $d_{i}^{r}$ is the total $\mathrm{CO}_{2}$ emissions of sector $i$ in region $r$. The embodied emissions term $\mathbf{f L Y}$ that driven by final demand of region $t$ in one sector in a specific region is normalized by the total emissions from the same sector of this region $\left(d_{i}^{r}\right)$, so that the CF hotspots $H^{t}$ are in absolute values that are consistent with $M$. As for the detailed derivation process, Supplementary Data 1 shows the spatial footprint approach.

As we focus on the actual emissions and CFs occurring in China's territory, we set the emission intensity of all sectors of all foreign regions as 0 in the calculation.

Reporting summary. Further information on research design is available in the Nature Research Reporting Summary linked to this article.

\section{Data availability}

The 2012 China MRIO table of 31 provincial units is compiled by the Key Laboratory of Regional Sustainable Development Analysis and Simulation, Chinese Academy of Sciences $^{23}$. The 2012 Full Eora model can be obtained from the Eora Global Supply Chain Database website (https://worldmrio.com/) ${ }^{24}, 37$. The spatially explicit gridded $\mathrm{CO}_{2}$ emissions of the China High Resolution Emission Database can be obtained from our previous study ${ }^{25}$. All datasets generated during this study are available from the corresponding author upon reasonable request.

\section{Code availability}

All computer codes generated during this study are available from the corresponding author upon reasonable request.

Received: 5 November 2019; Accepted: 2 April 2020; Published online: 07 May 2020

\section{References}

1. Liu, Z. et al. Targeted opportunities to address the climate-trade dilemma in China. Nat. Clim. Change 6, 201-206 (2016).

2. Kander, A., Jiborn, M., Moran, D. D. \& Wiedmann, T. National greenhousegas accounting for effective climate policy on international trade. Nat. Clim. Change 5, 431-435 (2015).

3. Peters, G. P., Minx, J. C., Weber, C. \& Edenhofer, O. Growth in emission transfers via international trade from 1990 to 2008. Proc. Natl Acad. Sci. USA 108, 8903-8908 (2011).

4. Davis, S. J., Peters, G. P. \& Caldeira, K. The supply chain of $\mathrm{CO}_{2}$ emissions. Proc. Natl Acad. Sci. USA 108, 18554-18559 (2011).

5. Moran, D. \& Kanemoto, K. Tracing global supply chains to air pollution hotspots. Environ. Res. Lett. 11, 094017 (2016).

6. Peters, G. From production-based to consumption-based national emission inventories. Ecol. Econ. 65, 13-23 (2008).

7. Zhang, Y. Provincial responsibility for carbon emissions in China under different principles. Energy Policy 86, 142-153 (2015).

8. Minx, J. C. et al. Input-output analysis and carbon footprinting: an overview of applications. Econ. Syst. Res. 21, 187-216 (2009).

9. Afionis, S., Sakai, M., Scott, K., Barrett, J. \& Gouldson, A. Consumption-based carbon accounting: does it have a future? Wiley Interdiscip. Rev.: Clim. Change 8, e438 (2017).

10. Steininger, K. W., Lininger, C., Meyer, L. H., Muñoz, P. \& Schinko, T. Multiple carbon accounting to support just and effective climate policies. Nat. Clim. Change 6, 35-41 (2016).

11. Baumert, N., Kander, A., Jiborn, M., Kulionis, V. \& Nielsen, T. Global outsourcing of carbon emissions 1995-2009: a reassessment. Environ. Sci. Policy 92, 228-236 (2019). 
12. Hertwich, E. G. \& Peters, G. P. Carbon footprint of nations: a global, tradelinked analysis. Environ. Sci. Technol. 43, 6414-6420 (2009).

13. Aichele, R. \& Felbermayr, G. Kyoto and the carbon footprint of nations. J. Environ. Econ. Manag. 63, 336-354 (2012).

14. Davis, S. J. \& Caldeira, K. Consumption-based accounting of $\mathrm{CO}_{2}$ emissions. Proc. Natl Acad. Sci. USA 107, 5687-5692 (2010).

15. Liang, S., Qu, S., Zhu, Z., Guan, D. \& Xu, M. Income-based greenhouse gas emissions of nations. Environ. Sci. Technol. 51, 346-355 (2017).

16. Wang, Z., Yang, Y. \& Wang, B. Carbon footprints and embodied $\mathrm{CO}_{2}$ transfers among provinces in China. Renew. Sustain. Energy Rev. 82, 1068-1078 (2018).

17. Feng, K. et al. Outsourcing $\mathrm{CO}_{2}$ within China. Proc. Natl Acad. Sci. USA 110, 11654-11659 (2013).

18. $\mathrm{Mi}, \mathrm{Z}$. et al. Chinese $\mathrm{CO}_{2}$ emission flows have reversed since the global financial crisis. Nat. Commun. 8, 1712 (2017).

19. Tian, X., Chang, M., Lin, C. \& Tanikawa, H. China's carbon footprint: a regional perspective on the effect of transitions in consumption and production patterns. Appl. Energy 123, 19-28 (2014).

20. Janssens-Maenhout, G. et al. EDGAR v4.3.2 Global Atlas of the three major greenhouse gas emissions for the period 1970-2012. Earth Syst. Sci. Data 11, 959-1002 (2019).

21. Kanemoto, K., Moran, D. \& Hertwich, E. G. Mapping the carbon footprint of nations. Environ. Sci. Technol. 50, 10512-10517 (2016).

22. Godar, J., Persson, U. M., Tizado, E. J. \& Meyfroidt, P. Towards more accurate and policy relevant footprint analyses: tracing fine-scale socio-environmental impacts of production to consumption. Ecol. Econ. 112, 25-35 (2015).

23. Liu, W., Tang, Z. \& Han, M. The 2012 China Multi-regional Input-output Table of 31 Provincial Units (China Statistics Press, Beijing, China, 2018).

24. Lenzen, M., Moran, D., Kanemoto, K. \& Geschke, A. Building EORA: a global multi-region input-output database at high country and sector resolution. Econ. Syst. Res. 25, 20-49 (2013).

25. Cai, B. et al. China high resolution emission database (CHRED) with point emission sources, gridded emission data, and supplementary socioeconomic data. Resour. Conserv. Recycl. 129, 232-239 (2018).

26. Boden, T., Andres, B. \& Marland, G. Fossil-Fuel $\mathrm{CO}_{2}$ Emissions by Nation from CDIAC (Carbon Dioxide Information Analysis Center). https://cdiac.ess-dive. lbl.gov/trends/emis/tre_coun.html (2017).

27. The Editorial Board of China Steel Yearbook. China Steel Yearbook 2014 (China Metallurgy Press, Beijing, China, 2014).

28. Müller, D. et al. Carbon emissions of infrastructure development. Environ. Sci. Technol. 47, 11739-11746 (2013).

29. World Bank. Gross Fixed Capital Formation (\% of GDP). Available at https:// data.worldbank.org/indicator/NE.GDI.FTOT.ZS (2019).

30. Berrill, P., Miller, T. R., Kondo, Y., \& Hertwich, E. G. Capital in the American carbon, energy, and material footprint. J. Ind. Ecol. https://doi.org/10.1111/ jiec.12953 (2019)

31. Shan, Y. et al. City-level climate change mitigation in China. Sci. Adv. 4, eaaq0390 (2018).

32. UNFCCC. FCCC/CP/2015/L.9/Rev.1: Adoption of the Paris Agreement. http:// unfccc.int/resource/docs/2015/cop21/eng/109r01.pdf (2015).

33. Moran, D. \& Kanemoto, K. Identifying species threat hotspots from global supply chains. Nat. Ecol. Evol. 1, 0023 (2017).

34. United States Trade Representative. Request for Comments Concerning Proposed Modification of Action Pursuant to Section 301: China's Acts, Policies, and Practices Related to Technology Transfer, Intellectual Property, and Innovation. https://ustr.gov/sites/default/files/enforcement/301Investigations/ 84_FR_22564.pdf (2019).

35. Belt and Road Portal. Overviews of Belt and Road Initiative Nations. https:// yidaiyilu.gov.cn/info/iList.jsp?cat_id=10037 (2020).

36. Rodrigues, J. F., Moran, D., Wood, R. \& Behrens, P. Uncertainty of consumption-based carbon accounts. Environ. Sci. Technol. 52, 7577-7586 (2018).

37. Lenzen, M., Kanemoto, K., Moran, D. \& Geschke, A. Mapping the structure of the world economy. Environ. Sci. Technol. 46, 8374-8381 (2012).
38. Wilting, H. C. Sensitivity and uncertainty analysis in MRIO modelling: some empirical results with regard to the Dutch carbon footprint. Econ. Syst. Res. 24 (2), 141-171 (2012).

39. The Editorial Board of China Ports Yearbook. China Ports Yearbook 2018 (China Ports Periodical Office, Shanghai, China, 2018).

40. Hummels, D. Transportation costs and international trade in the second era of globalization. J. Econ. Perspect. 21(3), 131-154 (2007).

41. Wang, J. et al. High resolution carbon dioxide emission gridded data for China derived from point sources. Environ. Sci. Technol. 48, 7085-7093 (2014).

42. Rodrigues, J., Marques, A., Wood, R. \& Tukker, A. A network approach for assembling and linking input-output models. Econ. Syst. Res, 28, 518-538 (2016).

43. Miller, R. E. \& Blair, P. D. Input-Output Analysis: Foundations and Extensions (2nd edn) (Cambridge University Press, Cambridge, UK, 2009).

\section{Acknowledgements}

S.Q. and M.X. thank the support from the Lieberthal-Rogel Center for Chinese Studies at University of Michigan. Y.Y. and Z.W. thank the support from the National Science Fund for Distinguished Young Scholars (71625003), National Natural Science Foundation of China (91746208), and National Key Research and Development Program of China (2016YFA0602504). S.L. thanks the support from National Natural Science Foundation of China (71874014)

\section{Author contributions}

S.Q. and M.X. designed the research. Y.Y., S.Q., B.C., and J.W. gathered the data. Y.Y., S.Q., S.L., Z.W., and M.X. performed the analysis and wrote the first draft of the paper. All authors contributed to writing the paper.

\section{Competing interests}

The authors declare no competing interests.

\section{Additional information}

Supplementary information is available for this paper at https://doi.org/10.1038/s41467 020-15883-9.

Correspondence and requests for materials should be addressed to S.Q.

Peer review information Nature Communications thanks Shinji Kaneko and Takako Wakiyama for their contribution to the peer review of this work.

Reprints and permission information is available at http://www.nature.com/reprints

Publisher's note Springer Nature remains neutral with regard to jurisdictional claims in published maps and institutional affiliations.

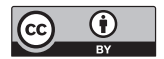

Open Access This article is licensed under a Creative Commons Attribution 4.0 International License, which permits use, sharing, adaptation, distribution and reproduction in any medium or format, as long as you give appropriate credit to the original author(s) and the source, provide a link to the Creative Commons license, and indicate if changes were made. The images or other third party material in this article are included in the article's Creative Commons license, unless indicated otherwise in a credit line to the material. If material is not included in the article's Creative Commons license and your intended use is not permitted by statutory regulation or exceeds the permitted use, you will need to obtain permission directly from the copyright holder. To view a copy of this license, visit http://creativecommons.org/ licenses/by/4.0/.

(C) The Author(s) 2020 